\title{
Analisis Keanekaragaman Tumbuhan Paku di Desa Kondo Bulo, Kecamatan Kalumpang, Kabupaten Mamuju
}

\author{
Widi Febrianti S*1, Phika Ainnadya Hasan², Arlinda Puspita Sari ${ }^{3}$ \\ Program Studi Pendidikan Biologi, Universitas Sulawesi Barat \\ e-mail: *phikahasan@unsulbar.ac.id
}

\begin{abstract}
Abstrak
Potensi tingkat keanekaragaman tumbuhan paku di wilayah Sulawesi yang cukup tinggi menyebabkan penelitian mengenai keanekaragaman tumbuhan paku telah sering dilakukan, akan tetapi penelitian keanekaragaman di provinsi Sulawesi Barat khususnya di Desa Kondo Bulo, Kecamatan Kalumpang, Kabupaten Mamuju masih belum pernah dilakukan. Penelitian ini bertujuan untuk menganalisis tingkat keanekaragaman tumbuhan paku dan hubungannya dengan parameter lingkungan, serta membandingkan jenis tumbuhan paku pada daerah pemukiman dan daerah hutan alami. Penelitian ini merupakan penelitian deskriptif eksploratif. Data dikumpulkan melalui metode Systematic Plot Sampling. Hasil menunjukan bahwa terdapat 16 jenis tumbuhan paku yang termasuk ke dalam 11 famili. Famili dengan jumlah jenis terbanyak adalah Polypodiaceae dan Pteridaceae. Nilai indeks habitat hutan alami yaitu $H^{\prime}=2,389$; $C=0,112 ; E=0,905$; dan $D M n=0,896$ dan nilai indeks habitat pemukiman yaitu $H^{\prime}=1,774$; $C=0,198 ; E=0,853$; dan $D M n=0,666$ dengan IS yang tergolong ke dalam sangat tidak mirip pada kedua habitat yaitu 1,2\%. Perbedaan nilai indeks disebabkan oleh faktor lingkungan seperti suhu, kelembaban, intensitas cahaya dan $\mathrm{pH}$ tanah.
\end{abstract}

Kata Kunci: Keanekaragaman, Kondo Bulo, Systematic Plot Sampling, Tumbuhan Paku

\section{PENDAHULUAN}

Tumbuhan paku merupakan tumbuhan yang sangat mudah ditemukan di berbagai tempat. Hal ini dikarenakan keanekaragaman tumbuhan mencapai \pm 10.000 jenis yang tersebar di berbagai penjuru dunia khususnya di kawasan negara tropis, termasuk di Indonesia (Pranita dkk, 2017). Tingkat keanekaragaman tumbuhan paku di wilayah Sulawesi memiliki potensi yang cukup tinggi. Di Sulawesi Utara, terdapat 21 jenis tumbuhan paku yang ditemukan di Kab. Bolaang, Mongondow Timur (Katili, 2013), 41 jenis yang ditemukan pada Cagar Alam Gunung Ambang (Arini dan Julianus, 2012) dan pada Sungai Tewalen, Minahasa Selatan tumbuhan paku memiliki kelimpahan jenis tertinggi kedua dengan persentase $13 \%$ dari 10 suku tumbuhan yang ditemukan (Bando dkk, 2016).

Menurut Tjitrosoepomo (1989), tumbuhan paku sebagian besar hidup di tempat-tempat teduh dengan derajat kelembaban yang tinggi. Wilayah Sulawesi Barat, memiliki kelembaban relatif yang mencapai 78\% dengan curah hujan hingga 1947.3mm³/tahun (Badan Pusat Statistik Provinsi Sulawesi Barat, 2019), menyebabkan Sulawesi Barat menjadi salah satu lokasi yang memiliki keanekaragaman tumbuhan paku. Penelitian mengenai keanekaragaman tumbuhan paku telah sejak lama dilakukan, akan tetapi dari semua penelitian yang ditemukan penelitian mengenai keanekaragaman tumbuhan paku di Sulawesi Barat khususnya di Desa Kondo Bulo, Kecamatan Kalumpang, Kabupaten Mamuju, Prov. Sulawesi Barat masih belum dilakukan. Oleh sebab itu peneliti mengambil penelitian ini, sehingga datanya dapat tersedia dan diketahui masyarakat luas pada umumnya. 


\section{METODE PENELITIAN}

\subsection{Waktu dan Tempat Penelitian}

Penelitian dilaksanakan pada September 2019 - Maret 2020 di Desa Kondo Bulo, Kecamatan Kalumpang, Kabupaten Mamuju, Prov. Sulawesi Barat. Identifikasi sampel dan analisis data dilakukan di Kabupaten Majene, Prov. Sulawesi Barat.

\subsection{Data Keanekaragaman Tumbuhan Paku}

Pengumpulan data keanekaragaman tumbuhan paku dibagi kedalam 2 titik penelitian yaitu (1) habitat hutan alami dan (2) habitat pemukiman dengan menggunakan metode Systematic Plot Sampling dengan ukuran $25 \mathrm{~m}^{2}(5 \mathrm{mx} 5 \mathrm{~m})$ sebanyak 6 plot untuk masing-masing titik dengan jarak antar plot $10 \mathrm{~m}$. Data jumlah dan jenis tumbuhan paku dianalisis dengan menghitung Indeks Keanekaragaman Shannon-Wiener (H'), Indeks Dominansi (C), Indeks Kemerataan (E), Indeks Kekayaan Jenis (DMn), dan Indeks Kesamaan Jenis (IS)

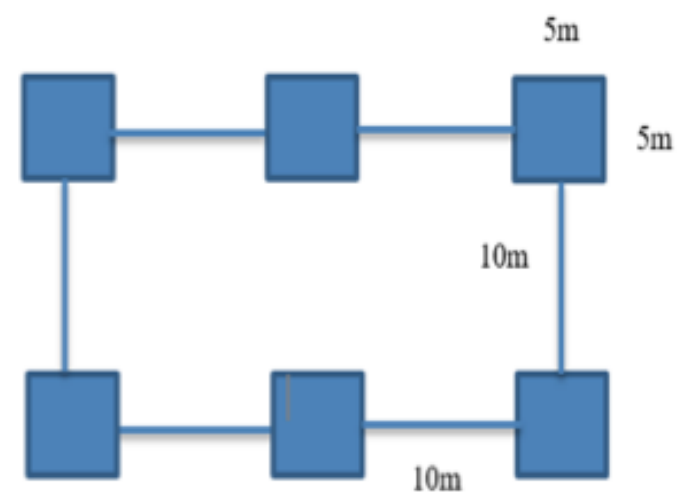

(a)

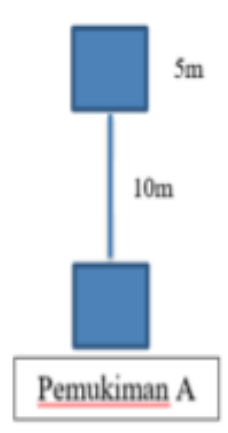

(b)

Gambar 1. Desain plot penelitian (a) hutan (b) pemukiman

\subsection{Data Parameter Lingkungan}

Pengumpulan data parameter lingkungan dilakukan dengan mengukur suhu dan kelembaban dengan termometer, intensitas cahaya dengan lux meter, serta $\mathrm{pH}$ tanah dengan soil tester yang dilakukan setiap hari. Data disajikan secara deskriptif.

\section{HASIL DAN PEMBAHASAN}

Hasil penelitian yang dilakukan pada 2 titik penelitian ditemukan 16 jenis tumbuhan paku yang termasuk kedalam 11 famili yaitu Adiantaceae, Aspleniaceae, Davalliaceae, Gleicheniaceae, Lomariopsidaceae, Lycopodiaceae, Polypodiaceae, Pteridaceae, Schizaeaceae, Selaginellaceae, dan Thelypteridaceae. Famili Polypodiaceae dan Pteridaceae masing-masing memiliki jumlah jenis terbanyak yaitu 3 jenis, sedangkan famili Schizaeaceae memiliki 2 jenis, dan famili lainnya hanya memiliki 1 jenis. 

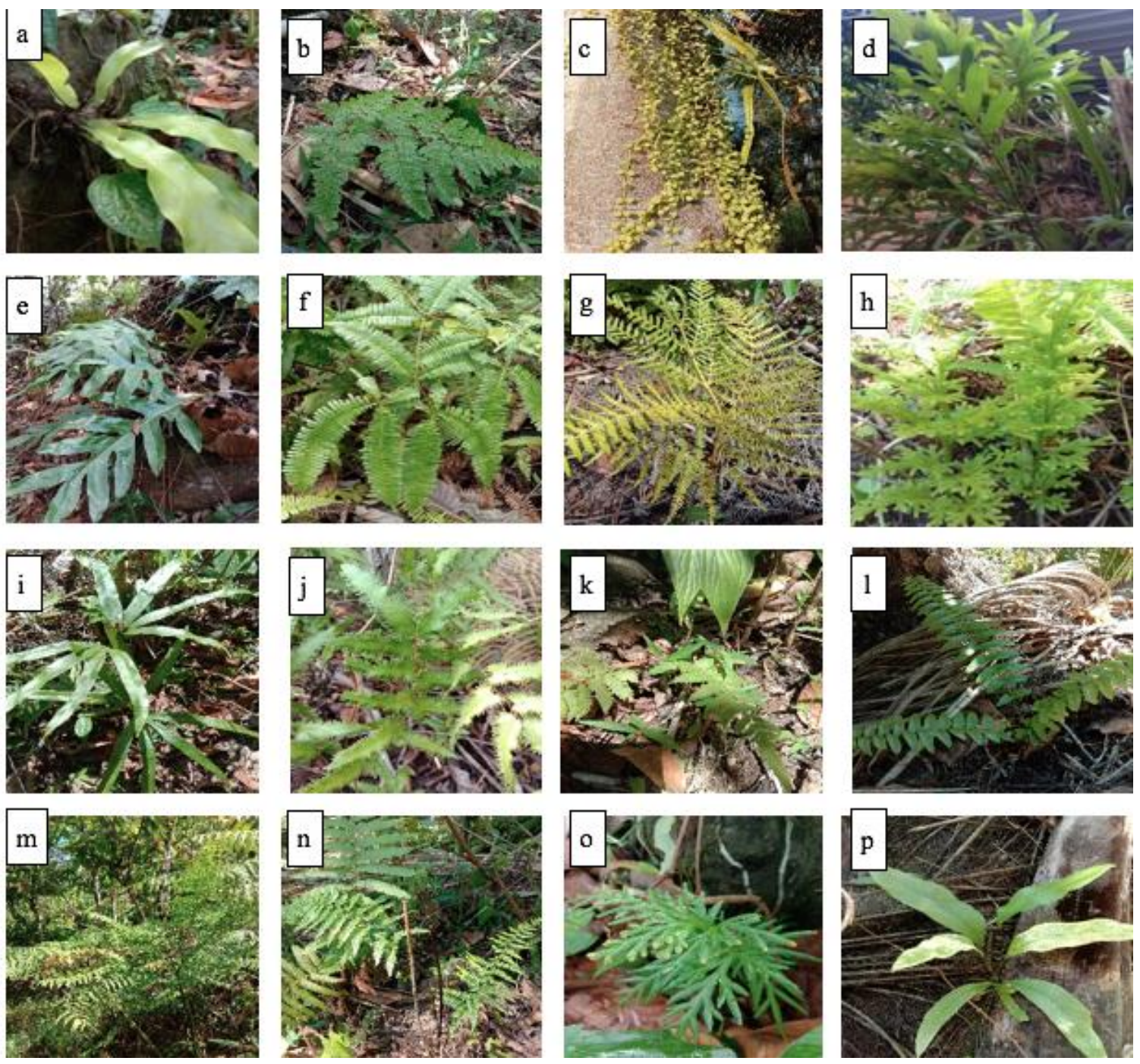

Gambar 2. Jenis tanaman paku yang ditemukan. (a) Asplenium nidus (b) Davallia denticulata (c) Drymoglossum piloselloides (d) Drynaria parishii (e) Drynaria quercifolia (f) Gleichenia linearis (g)

Histiopteris incisa (h) Lycopodium cernuum (i) Lygodium circinnatum (j) Lygodium flexuosum (k)

Parathelypteris japonica (1) Pteridium esculentum (m) Pteris tripartita (n) Pityrogramma calomelanos (o) Selaginella intermedia (p) Syngramma alismifolia.

Jenis yang paling banyak ditemukan adalah Selaginella intermedia yakni 68 individu. Jenis yang paling sedikit ditemukan adalah Drymoglossum piloselloides yakni 1 individu. Jenis ini memiliki jumlah individu yang paling sedikit disebabkan karena kurang sesuainya kondisi lingkungan untuk pertumbuhan. Drymoglossum piloselloides membutuhkan cahaya matahari dalam jumlah yang banyak (Katili, 2013) sedangkan di lokasi penelitian intensitas cahaya maksimum hanya 46600 Lux dengan suhu minimum $27,8^{\circ} \mathrm{C}$. Hal serupa juga dilaporkan oleh Mentari (2019) yang menemukan bahwa Drymoglossum piloselloides adalah salah satu jenis yang paling sedikit ditemukan (1 individu) pada suhu $27,1^{\circ} \mathrm{C}$.

Jenis yang paling banyak ditemukan pada habitat alami adalah Lycopodium cernuum yakni 55 individu. Jenis tumbuhan paku ini mudah dijumpai pada habitat terbuka maupun tertutup, bahkan didaerah kering dan miskin unsur hara (Jamsuri, 2007) oleh karena itu Lycopodium cernuum dapat hidup dimanapun. Berdasarkan data yang dikumpulkan, Lycopodium cernuum merupakan jenis yang hidup subur pada habitat 
alami dengan suhu $25,5^{\circ} \mathrm{C}$ hingga $30,6^{\circ} \mathrm{C}$. Hal ini didukung oleh Wanma (2016) yang menemukan bahwa Lycopodium cernuum hidup mulai pada suhu $17^{\circ} \mathrm{C}$.

Jenis yang paling banyak ditemukan pada habitat pemukiman adalah Selaginella intermedia yakni 43 individu. Hal ini terjadi karena Selaginella intermedia dapat dengan mudah untuk tumbuh pada permukaan tanah kering hingga lembab sehingga dapat secara cepat menutupi permukaan tanah (Syafrudin dkk, 2016) dengan kebutuhan intensitas yang cahaya lebih rendah (Katili, 2013). Kondisi tersebut sesuai dengan data yang dikumpulkan, dimana habitat pemukiman memiliki suhu $27,8^{\circ} \mathrm{C}$ hingga $32,4^{\circ} \mathrm{C}$ yang sangat sesuai untuk pertumbuhan Selaginella intermedia. Hal ini didukung oleh Wanma (2016) yang menemukan bahwa Selaginella intermedia adalah salah satu jenis yang paling banyak ditemukan bahkan pada suhu

(a)

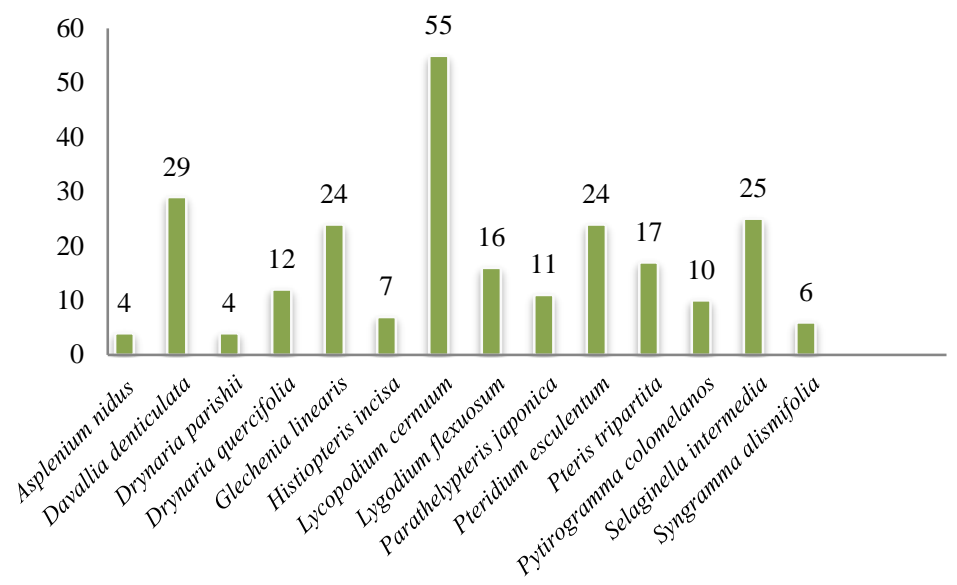

(b)

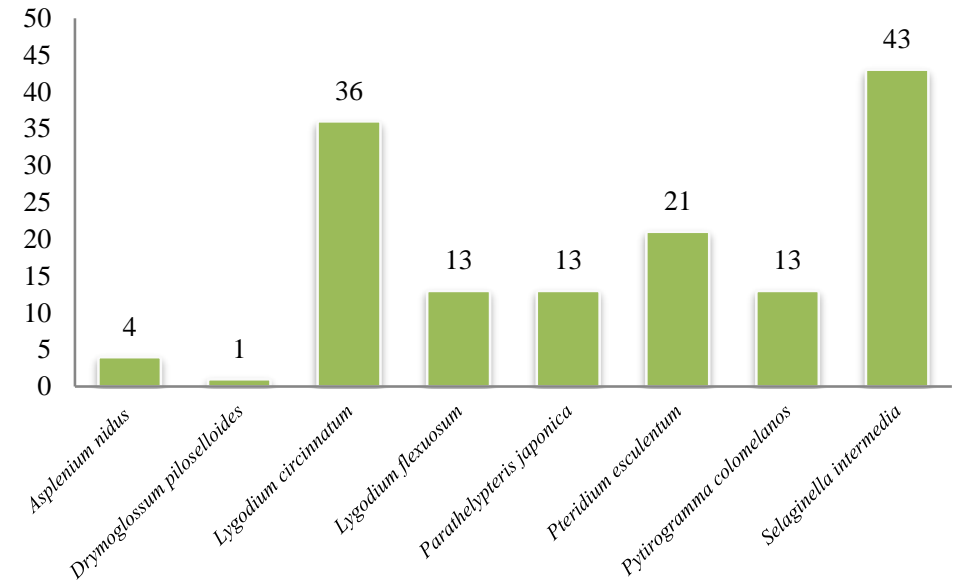

Gambar 3. Jumlah tumbuhan paku di titik (a) daerah hutan alami, dan (b) pemukiman

Nilai indeks Indeks Keanekaragaman (H') dan Indeks Kemerataan (E) pada titik pengamatan di habitat alami lebih besar $(2,389$ dan 0,905) dibandingkan dengan titik pengamatan di habitat pemukiman (1,774 dan 0,853). Lalu untuk Indeks Dominansi (C) kedua habitat mendekati $0(0,112$ dan 0,198) dengan Indeks Kekayaan Jenis (DMn) yang lebih besar pada habitat alami $(0,896)$. Kedua titik pengamatan digolongkan kedalam tingkat keanekaragaman jenis $\left(\mathrm{H}^{\prime}\right)$ yang sedang. Tidak didominasi $(\mathrm{C})$ oleh jenis tertentu. Kemerataan populasi (E) yang tinggi. Kekayaan jenis (DMn) yang tinggi dan kesamaan jenis (IS) yang sangat tidak mirip. 


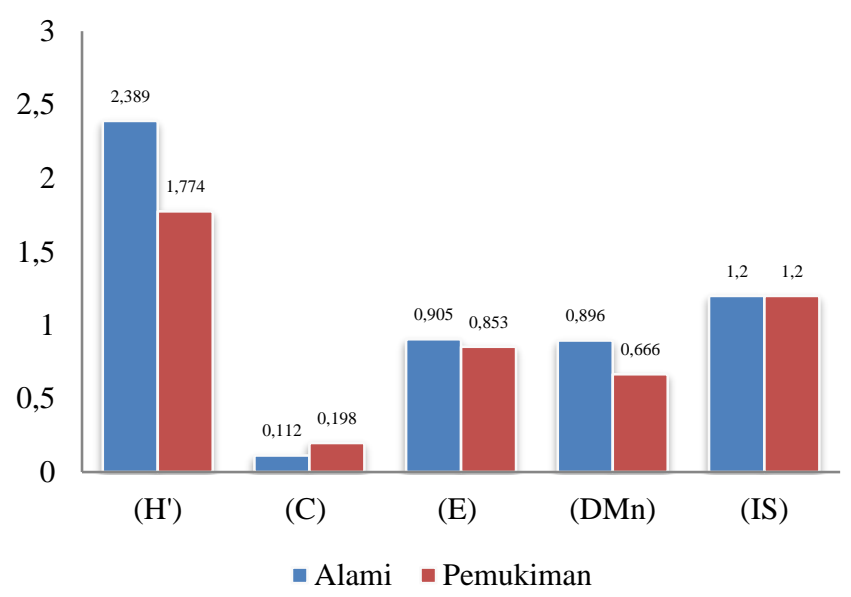

Gambar 4. Nilai Indeks Keanekaragaman Shannon-Wiener (H'), Indeks Dominansi (C), Indeks Kemerataan (E), Indeks Kekayaan Jenis (DMn), dan Indeks Kesamaan Jenis (IS)

Tabel 1. Data parameter lingkungan.

\begin{tabular}{|c|c|c|c|c|c|c|c|c|c|c|}
\hline \multirow{2}{*}{$\begin{array}{c}\text { Titik } \\
\text { Pengamatan }\end{array}$} & \multicolumn{3}{|c|}{ Suhu $\left({ }^{\circ} \mathrm{C}\right)$} & \multicolumn{3}{|c|}{ Kelembaban (\%) } & \multicolumn{3}{|c|}{ Intensitas Cahaya (Lux) } & \multirow[t]{2}{*}{ pH } \\
\hline & Min & Mak & Rerata & Min & Mak & Rerata & Min & Mak & Rerata & \\
\hline Alami & 25,5 & 30,6 & 28,3 & 64 & 77 & 70 & 12200 & 18800 & 16300 & 6 \\
\hline Pemukiman & 27,8 & 32,4 & 29,3 & 62 & 72 & 68 & 15500 & 46600 & 19200 & 6 \\
\hline
\end{tabular}

Dari parameter lingkungan menunjukkan bahwa titik pengamatan di habitat alami memiliki kelembaban maksimal (77\%) yang lebih tinggi dibandingkan dengan titik pengamatan di habitat pemukiman $(72 \%)$. Hal ini disebabkan karena suhu minimum $\left(25,5^{\circ} \mathrm{C}\right)$ dan suhu maksimum $\left(30,6^{\circ} \mathrm{C}\right)$ di habitat alami lebih rendah daripada suhu minimum $\left(27,8^{\circ} \mathrm{C}\right)$ dan suhu maksimum $\left(32,4^{\circ} \mathrm{C}\right)$ di habitat pemukiman. Selain itu intensitas cahaya di habitat pemukiman (46600 Lux) lebih tinggi daripada di habitat alami (18800 Lux).

\section{KESIMPULAN}

Kesimpulan penelitian ini adalah terdapat 16 jenis tumbuhan paku yang termasuk ke dalam 11 famili di Desa Kondo Bulo, Kecamatan Kalumpang, Kabupaten Mamuju. Nilai indeks Indeks Keanekaragaman (H') dan Indeks Kemerataan (E) pada titik pengamatan di habitat alami lebih besar $(2,389$ dan 0,905) dibandingkan dengan titik pengamatan di habitat pemukiman (1,774 dan 0,853). Lalu untuk Indeks Dominansi (C) kedua habitat mendekati $0(0,112$ dan 0,198) dengan Indeks Kekayaan Jenis (DMn) yang lebih besar pada habitat alami $(0,896)$. Penelitian ini merupakan penelitian mengenai tumbuhan paku yang pertama kali dilakukan, oleh sebab itu penelitian ini masih sangat banyak memiliki kekurangan sehingga perlu dilakukan penelitian lebih lanjut untuk mendapatkan data keanekaragaman di seluruh Kabupaten Mamuju maupun Sulawesi Barat.

\section{DAFTAR PUSTAKA}

Arini, D. I. D. \& Julianus, K. 2012. Keragaman Jenis Tumbuhan Paku (Pteridophyta) Di Cagar Alam Gunung Ambang Sulawesi Utara. Balai Penelitian Kehutanan Manado. 1 (2), 17-40.

Badan Pusat Statistik Provinsi Sulawesi Barat. 2019. Rata-Rata Suhu Udara, Kelembaban, Tekanan Udara, Kecepatan Angin, Curah Hujan, dan Penyinaran Matahari Menurut Stasiun di Provinsi Sulawesi Barat, 2016-2017. Badan Pusat Statistik Provinsi Sulawesi Barat. Diakses dari sulbar.bps.go.id 
https://jurnal.unsulbar.ac.id/index.php/saintifik

Bando, A. H., Ratna, S. \& Marnix, L. D. L. 2016. Keanekaragaman Vegetasi Riparian Di Sungai Tewalen, Minahasa Selatan - Sulawesi Utara. Jurnal Ilmiah Sains. 1 (16), 7-11.

Jamsuri. 2007. Keanekaragaman Tumbuhan Paku Di Sekitar Curug Cikaracak, Bogor, Jawa Barat. [Skripsi]. Universitas Islam Negeri Syarif Hidayatullah Jakarta.

Katili, A. S. 2013. Deskripsi Pola Penyebaran Dan Faktor Bioekologis Tumbuhan Paku (Pteridophyta) Di Kawasan Cagar Alam Gunung Ambang Sub Kawasan Kabupaten Bolaang Mongondow Timur. Jurnal Saintek Universitas Negeri Gorontalo. 2 (7), 1-13.

Mentari, D. 2019. Keanekaragaman Tumbuhan Paku (Pteridophyta) Di Kawasan Air Terjun Malaka Desa Lam Ara Tunong Kabupaten Aceh Besar Sebagai Referensi Pembelajaran Kingdom Plantae Di MAN 1 Aceh Besar. [Skripsi]. Universitas Islam Negeri Ar-Raniry Banda Aceh.

Pranita, H. S., Susriyati. M. \& Murni, S. S. 2017. Karakteristik Spora Tumbuhan Paku Asplenium Kawasan Hutan Raya R. Soerjo. Jurnal Pendidikan: Teori, Penelitian, dan Pengembangan. 4 (2), 454-458.

Syafrudin, Y., Tri, S.H. \& Sri, W. 2016. Keanekaragaman Dan Potensi Paku (Pteridophyta) Di Taman Nasional Gunung Gede Pangrango Cianjur (TNGGP). Ekologia. 2 (16), 24-31.

Tjitrosoepomo, G. 1989. Taksonomi Tumbuhan Schizophyta, Thallophyta, Bryophyta, Pteridophyta. Yogyakarta: Gadjah Mada University Press.

Wanma, A.O. 2016. Keanekaragaman Jenis Tumbuhan Paku (Pteridophyta) Di Gunung Arfak Papua Barat. [Tesis]. Institut Pertanian Bogor. 